\title{
Cytotoxic and Antioxidant Activities of the Volatile Constituents of Brassica tournefortii Gouan: Growing in Egypt
}

\author{
Marwan. M. Shabana, Fifi. I. Fathy, Maha M. Salama * and M. M. Hashem \\ Department of Pharmacognosy, Cairo University, Egypt
}

Received: December 06, 2013; Accepted: December 21, 2013; Published: December 23, 2013

*Corresponding author: Maha M. Salama, Department of Pharmacognosy, Faculty of Pharmacy, Cairo University, Kasr-el-Aini St., 11562, Egypt, E-mail: salamamaha@hotmail.com

\begin{abstract}
The volatile constituents of the seeds of Brassica tournefortii Gouan, growing in Egypt -prepared by simultaneous solvent extraction (steam distillation using Likens-Nickerson type apparatus (SSD-SE) technique) - were investigated by GC/MS analysis. This resulted in the identification of 14 compounds which amount to $76.1 \%$ of the total percentage components detected in essential oil of the seeds. Results revealed that the oil was rich in sulphur compounds represented by di-2-propenyltetrasulfide (19.803\%) and 3-(methylthio) propyl isothiocyanate (24.39\%). Consequently, the cytotoxic activity against two human cancer cell lines; breast (MCF7) and colon (HCT116) were tested and significant results $\left(\mathrm{IC}_{50}=1.34\right.$ and $4.5 \mu \mathrm{gmL}^{-1}$ respectively) were obtained. On the other hand, the in vitro anti oxidant activity was also tested exhibiting significant free radical scavenging effects $\left(\mathrm{IC}_{50}=45.17 \mu \mathrm{g} / \mathrm{mL}\right)$ compared to vitamin c $(75.28 \mu \mathrm{g} / \mathrm{mL})$ which was used as a reference.
\end{abstract}

Keywords: Brassica tournefortii Gouan; Cytotoxic activity; MCF7; HCT116; Free radical scavenging activity

\section{Introduction}

Family Crucifereae (Mustard family, Brassicaceae) [1], is a worldwide distribution. It comprises about 375 genera and 3200 species. Brassica is an importantgenus in the family. The members of the genus are collectively known as cruciferous vegetables as; cabbages, cauliflower, broccoli and brussels sprouts or mustards [2]. Cruciferous vegetables have been extensively studied due to their typical flavor and odor, attributed to volatile sulphur and nitrogen-containing compounds. These vegetables have been reported to lower the risk of developing various cancers [3].

Brassica tournefortii (Gouan) F. Crucifereae is an annual herb. It is also known as Asian mustard, Sahara mustard, Moroccan mustard, African mustard, Mediterranean mustard, Mediterranean turnip, wild turnip, desert mustard, southwestern mustard, Tournefort's mustard, prickly turnip, turnip weed [4]. It grows widely in sandy and loam field, gardens, Mediterranean coastal strip from El-Saloum to Rafah, Sinai proper (El-Tih desert) and Oases of the Libyan Desert [5].

Cancer is a major public health problem in both developed and developing countries. Since 1990 , there has been a $22 \%$ increase in cancer incidence and mortality with the four most frequent cancers being lung, breast, colorectal, and stomach $[6,7]$. Breast cancer is the most frequent malignant tumor in women worldwide. In Egypt, it is the most common cancer among women, representing $18.9 \%$ of total cancer cases recorded by the National Cancer Institute in Egypt (NCI) [8]. On the other hand, colorectal cancer is the third most commonly diagnosed and the second leading cause of cancer death in men and women combined in US. In Egypt, colorectal carcinoma is uncommon, but a high proportion of cases occur before age 40 years and mainly in the rectum [9].

Medicinal plants have played important roles in the last five decades in the treatment of cancer and most new clinical applications of plant secondary metabolites and their derivatives have been applied towards combating cancer.

In that respect and since no reports dealt with the chemical composition of the essential oil from B. touernefortii Gouan., the aim of this paper is therefore to determine and identify the steam volatiles content of the seeds of $B$. tournefortii Gouan. Furthermore, cytotoxic activity against breast and colon human cancer cell line, antioxidant capacity in scavenging 2,2 diphenyl 1-picrylhydrazyl (DDPH) were also studied.

\section{Material and Methods}

\section{Plant materials}

Brassica tournefortii Gouan is collected from Cairo-Alex Desert road in March 2007. The plant was kindly authenticated by Prof. Dr. Mohammed El-Gebaly, Senior botanist, El-Orman garden, Giza, Egypt. A voucher specimen (No. BT-2009) is kept in the herbarium museum of the Pharmacognosy Department, Faculty of Pharmacy, Cairo University, Egypt.

\section{Chemicals}

All chemical reagents were of analytical grade and all solvent were of GC and HPLC grade. DDPH and vitamin C standards were purchased from Sigma-Aldrich St. Louis, MO, USA)

The human breast (MCF7) and colon (HCT116) cancer cell line was obtained frozen in liquid nitrogen $(-1800 \mathrm{C})$ from the American Type Culture Collection. The tumor cell lines were 
maintained in the National Cancer Institute, Cairo, Egypt, by serial sub-culturing.

\section{Preparation of volatile constituents}

A sample of the seeds (100 g) was crushed and placed in a $1 \mathrm{~L}$ flask with $0.5 \mathrm{~L}$ of water (to allow enzymatic degradation of glucosinolates to sulphur containing Compounds). The mixture was subjected to simultaneous solvent extraction-steam distillation using a Likens-Nickerson type apparatus for $5 \mathrm{~h}$, using diethyl ether as the extracting solvent to yield yellowish oil $(0.2 \mathrm{ml})$, which was dried over anhydrous sodium sulphate. The extract was stored at low temperature $\left(-4^{\circ} \mathrm{C}\right)$ prior to GC/ MS analysis

\section{GC/MS analysis}

Investigation of the prepared oil was carried out by GC/ MS on SHIMADZU GC/MS-QP system. The instrument was equipped with $\mathrm{DB}_{1}$ column, (30 MX 0.53 i.d., $1.5 \mu \mathrm{m}$ film thickness); carrier gas, helium, with $1 \mathrm{ml} / \mathrm{min}$., flow rate; detector used, FID; sample size, $0.5 \mu \mathrm{l}$; injector temperature, $25^{\circ} \mathrm{C}$; detector temperature, $280^{\circ} \mathrm{C}$; oven temperature program, $40^{\circ} \mathrm{C}(1 \mathrm{~min})-.150^{\circ} \mathrm{C}(1 \mathrm{~min}$. $)$ at $7.5^{\circ} \mathrm{C} / \mathrm{min}-250^{\circ} \mathrm{C}(2 \mathrm{~min}$. $)$ at $1.2^{\circ} \mathrm{C} / \mathrm{min}$. Ionization mode, $\mathrm{EI}$ mass ionization voltage was $70 \mathrm{ev}$. The start-stop masses were 30-500 aum.

The constituents of the oils were identified by comparing their retention times, Kovat's indices and mass fragmentation patterns with those of available reference samples, GC/MS database, spectrometric electronic libraries (Wiley138, NIST, NBS) and comparing with the published data [10,11]. Kovat's retention indices of the compounds were calculated relative to the retention times of a series of $n$-paraffin hydrocarbons with a logarithmic scale [12]. Relative percentages were calculated from the Total Ion Chromatograms by the computerized integrator.

Results of the GC/MS analysis were recorded in the Table 1.

\section{Assessment of cytotoxic activity}

Cells were placed in a 96-multiwell plate $\left(10^{4}\right.$ cells/well) in a fresh medium for 24 hours before treatment with the samples. Different concentrations of the samples under investigation $(0$, $1,2.5,5$ and $10 \mu \mathrm{g} / \mathrm{ml}$ ) were added to the cells. Triplicate wells were prepared for each individual concentration. The cells were re-incubated with the samples for an additional 48 hours at $37^{\circ} \mathrm{C}$ in an atmosphere of $5 \% \mathrm{CO}_{2}$. After 48 hours, cells were fixed with trichloroacetic acid, washed and stained with $0.4 \%(\mathrm{w} / \mathrm{v})$ Sulphorhodamine-B (SRB) stain. Excess stain was removed by four washes with $1 \%$ acetic acid to remove unattached dye. The protein-bound dye was recovered using unbuffered Tris EDTA. Cytotoxicity was assessed using Sulphorhodamine-B (SRB) assay [13]. The optical density (O.D.) of each well was measured spectrophotometrically at $564 \mathrm{~nm}$ with an ELIZA microplate reader (Meter tech. $\Sigma$ 960, U.S.A.).The percentage of cell survival was calculated as follows:

Survival fraction $=$ O.D. $($ treated cells $) /$ O.D. $($ control cells $)$. The $\mathrm{IC}_{50}$ values (the dose of the oil which reduces survival to $50 \%)$. The experiment was repeated 3 times for each cell line [13].

\section{Antioxidant activity}

Antioxidant activity was assayed using a modified quantitative 2,2-diphenyl-1-picrylhydrazyl DDPH assay [14]. The solution of DDPH was prepared using HPLC grade methanol and DDPH (sigma-aldrich) at a concentration of $0.004 \%$. Lyophilized extract was dissolved in water at concentration of 1-100 $\mathrm{mg} \mathrm{mL}^{-1}$ with $5 \mu \mathrm{L}$ of each tested solution added to $100 \mathrm{ml}$ of DDPH solution. A blank sample was run using HPLC grade methanol. After 30 minute incubation period at room temperature, the absorbance was read against a blank at $550 \mathrm{~nm}$. Vitamin C (sigma-aldrich) was used as positive control at a concentration of 1-100 $\mathrm{mg} \mathrm{mL}^{-1}$. Antioxidant activity is expressed as the concentration of extract

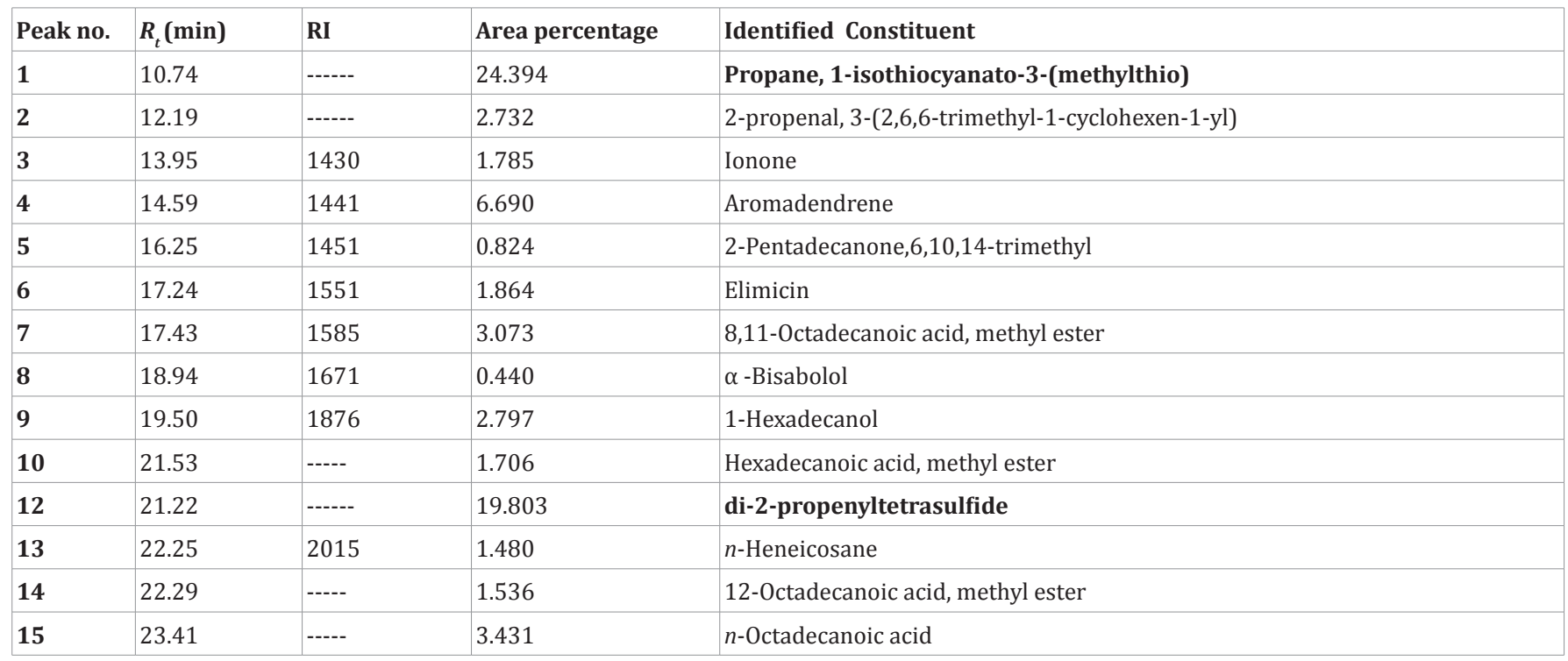

$\mathrm{M}^{+}$: Molecular ion peak; $\mathrm{m} / \mathrm{z}$ : mass/charge ratio; $\mathrm{R}_{\mathrm{t}}$ : Retention time. RI: Retention index

Table 1: Results of GC/MS analysis of the volatile constituents of the seeds of Brassica tournefortii (Gouan). 
inhibiting DDPH formation by $50 \%$ relative to methanol $\left(\mathrm{IC}_{50}\right.$ value). Inhibition of the DDPH free radical in percent (I \%) was calculated according to this formula:

$$
I \%=\left[\left(A_{\text {blank }}-A_{\text {sample }}\right) / A_{\text {blank }}\right] \times 100
$$

$A_{\text {blank }}$ is the absorbance of the control reaction and $A_{\text {sample }}$ is the absorbance of the extract. Values are expressed as $\mathrm{IC}_{50}$. Each measurement was performed in duplicate.

\section{Results and Discussion}

The steam volatile constituents collected by simultaneous solvent extraction-steam distillation using a Likens-Nickerson type apparatus from B. tournefortii Gouan. was obtained as yellow oil with disagreeable odor, in a yield of $0.04 \%$. GC/MS analysis of the oils (Table 1 ) showed the presence of 14 compounds, representing $72.55 \%$ of the total constituents of the essential oil. The oil was dominated by sulphur compounds amounting to $52.9 \%$ which could be responsible for the odor of the oil. They were represented as 3-(methylthio) propyl isothiocyanate $24.394 \%$ (this compound was obtained from the hydrolysis of Glucoiberverin glucoside) [15] and di-2-propenyltetrasulfide (19.803\%) from thermal degradation of S- methyl cysteine sulfoxide [16-19].

Other detected constituents were ionone $1.7 \%$, elemicin $1.864 \%$ and aromadendrene $6.69 \%$.

In recent years, cancer prevention by natural products has received considerable attention. The potential protective role of cruciferous vegetables and active components present in these vegetables, such as isothiocyanates and indole-3-carbinol, has been extensively studied. Results have consistently shown that the chemopreventive agents derived from this class of vegetables of the Cruciferae family influence carcinogenesis during initiation and promotion phases of cancer development [20]. Other studies support that the anticarcinogenic mechanisms that have been revealed for isothiocyanates is the inhibition of cell proliferation [21]. The cytotoxic activity of the volatile extract of the seeds of B. tournefortii Gouan. was tested against breast (MCF7) and colon (HCT116) human cancer cell line. The volatile extracts showed pronounced cytotoxic activity against breast (MCF7) (Figure 1) and colon (HCT116) (Figure 2) human cell line with IC $_{50} 1.34$ and $4.5 \mu \mathrm{gmL}^{-1}$ respectively. This activity could be attributed to the isothiocyanates (ITCs) which represent an important and promising chemopreventive compound [22-27]. In recent years, numerous investigations have shown that sulfur-containing compounds induce apoptosis in multiple cell lines (including breast and colorectal cell line) and experimental animals [28].

Oxidative stress may initiate molecular events in the cancer process, and reduction of oxidative stress may protect against carcenogensis [29]. Crucifers contain numerous antioxidant substances that potentially induce oxidant enzymes, and combination of theses may protect against carcenogensis [30]. The B. tournefortii Gouan. volatile extract was assessed for its capacity to scavenge DDPH free radical along with vitamin $\mathbf{C}$ as positive control. The oil reduced the concentration of DPPH with an $\mathrm{IC}_{50}$ value of $45.17 \mu \mathrm{g} / \mathrm{mL}$, which was lower than that of

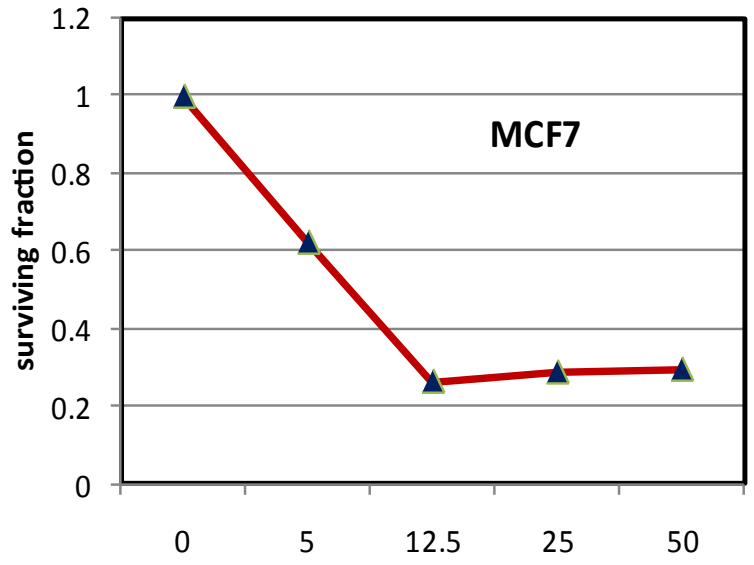

Figure 1: The relation between the surviving fraction of Breast human cell line and the concentrations of the volatile extracts of the seeds the B. tournefortii.

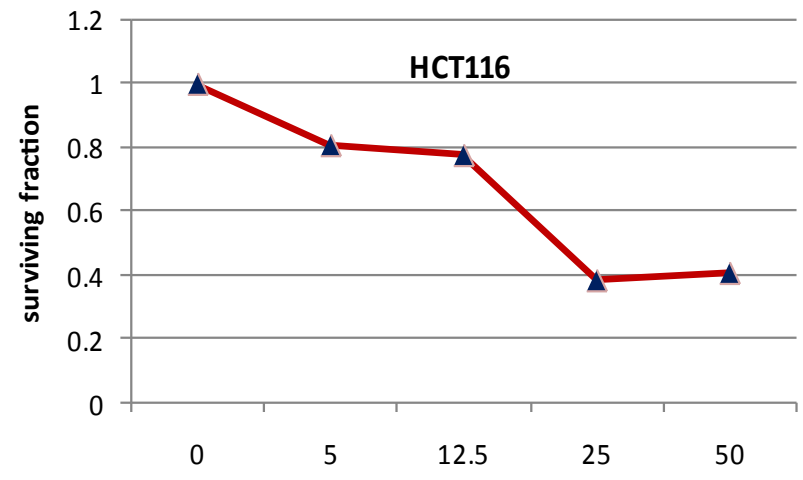

Figure 2: The relation between the surviving fraction of colon human cell line and the concentrations of the volatile extracts of the seeds of the B. tournefortii.

vitamin-C, with an $\mathrm{IC}_{50}$ of $75.28 \mu \mathrm{g} / \mathrm{mL}$ this showed that the oil has moderate antioxidant activity related to vitamin-C. These findings support the cytotoxic activity of the volatile constituents obtained from Brassica tournefortii Gouan might also be attributed to the antioxidant activity revealed by oxygenated and sulphur constituents of the oil. These effects together with the previous reported mechanism of action of sulphur compounds suggest the use of Brassica tournefortii as a chemopreventive natural drug. This is the first report of isolation and cytotoxic activity of the oil from Brassica tournefortii Gouan.

\section{Conclusion}

GC-MS study of volatile extracts from Brassic tournefortii Gouan. seeds led to the identification of 14 compounds. The Formation of the identified isothiocyanate derivative (3-(methylthio) propyl isothiocyanate) can be explained by the hydrolysis of Glucoiberverin glucoside Results evidenced the correlation between crucifer vegetables and potent cancerpreventive therefore, introducing $B$. touernefortii as a new herbal 
chemopreventive candidate for growth inhibition of the two studied types of cell lines.

\section{References}

1. Evans WC (2002) Trease and Evans Pharmacognosy. (15thedn), London, New York, Philadelphia, pp. 25, 188, 473.

2. Buttery RG, Guadagni DG, Ling LC, Seifert RM, Lipton W (1976) Additional volatile components of cabbage, broccoli and cauliflower. J Agric Food Chem 24(4): 829-832.

3. Matusheski NV, Wallig MA, Juvik JA, Klein BP, Kushad MM et al. (2001) Preparative HPLC method for the purification of sulforaphane and sulforaphane nitrile from Brassica oleracea. J. Agric. Food Chem. 49(4): 1867-1872.

4. Halvorson WL (2003) USGS Weeds in the West project: Status of Introduced Plants in Southern Arizona Parks Fact sheet for: Brassica tournefortii Gouan. 3-6.

5. Boulos L (2005) Flora of Egypt. Al-Hadara Publishing. Dokki 12311 Cairo, Egypt.

6. Parkin DM, Bray F, Ferlay J, Pisani P (2001) Estimating the world cancer burden- Globocan 2000. Int J Cancer 94(2): 153-156.

7. Balunas MJ, Kinghorn AD (2005) Drug discovery from medicinal plants. Life Sci 78(5): 431-441.

8. Salem AAS, Salem MAE, Abbass H (2010) Breast Cancer: Surgery at the South Egypt Cancer Institute. Cancers, 2(4): 1771-1778.

9. Soliman AS, Bondy ML, El-Badawy SAN, Mokhtar N, Eissa, S, et al (2001) Contrasting molecular pathology of colorectal carcinoma in Egyptian and Western patients. British J. Cancer. 85(7): 1037-1046.

10. Adams RP (2004) Identification of essential oil components by gas chromatography/mass spectroscopy. Allured Publishing Corporation: Illinois, USA.

11. Wiley7 Nist 05.L-version and in the NIST05.L data bases.

12.Jenning W, Shibamoto T (1980) Qualitative Analysis of Flavor and Fragrances Volatiles by Glass Capillary Gas Chromatography. Academic Press, New York

13. Skehan P, Storeng R, Scudiero D, Monks A, McMahom JM et al. (1990) New colourimetric cytotoxicity assay for anti-cancer drug screening. J natl. Cancer Inst. 82(13): 1107-1112.

14. Shimada K, Fujikawa K, Yahara K, Nakamura T (1992) Antioxidative properties of xanthan on the autoxidation of soybean oil in cyclodextrin emulsion. J. Agric. Food Chem. 40(6): 945-948.

15. Bennett RN, Fred AM, Paul A K (2004) Screening crucifer seeds as sources of specific intact glucosinolates using ion-pair highperformance liquid chromatography negative ion electrospray mass spectrometry. J. Agric. Food Chem. 52(3): 428-438.

16. Synge RLM, Wood JC (1956) (+)- (S- Methyl -L- Cysteine S- sulfoxide) in Cabbage. Biochem. J. 64(2): 252-259.
17. Arnold WN, Thompson JF (1962) The formation of (+) S- methyl cysteine from s- methyl L-cysteine in crucifers. Biochem. Bio. Phys. Acta 57(1): 604-606.

18. Gustine DL (1985) Determination of S-methyl cysteine sulfoxide in Brassica extracts by high performance liquid chromatography. J. chromatog 319(3): 450-453.

19. Farag MA, Motaal AA (2009) Sulphorane composition, cytotoxic and antioxidant activity of crucifer vegetables. JAR 1(1): 65-70.

20. Murillo G, Mehta RG (2001) Cruciferous vegetables and cancer prevention. Nutr. Cancer. 41(1-2): 17-28.

21. Zhang Y, Li Tang, Gonzalez V (2003) Selected isothiocyanates rapidly induce growth inhibition of cancer cells. Mol Cancer Ther 2(10): 104552.

22. Hecht SS (2004) Chemoprevention by Isothiocyanates. In: Kelloff GJ, Hawk ET, Sigman CC Promising Cancer Chemopreventive Agents, Volume 1: Cancer Chemopreventive Agents. Totowa, NJ: Humana Press, 21-35.

23. Nakamura Y, Miyoshi N (2006) Cell death induction by isothiocyanates and their underlying molecular mechanisms. Biofactors: 26(2): 123134

24.Zhang Y, Yao S, Li J (2006) Vegetable-derived isothiocyanates: antiproliferative activity and mechanism of action. Proc Nutr Soc. 65(1): 68-75.

25.Tseng E, Scott-Ramsay EA, Morris ME (2004) Dietary Organic Isothiocyanates are cytotoxic in Human breast cancer MCF-7 and mammary epithelial MCF-12A cell lines. Exp Biol Med (Maywood) 229(8): 835-842

26. Verhoeven DTH, Goldbohm AR, Poppel GV, Verhagen H, van den Brandt PA (1997) A review of mechanisms underlying anticarcinogenicity by brassica vegetables. Chemico-Bioll Interact 103(2), 79-129.

27. Wu X, Kassie F, Mersch-Sundermann V (2005) Induction of apoptosis in tumor cells by naturally occurring sulfur-containing compounds. Mutat Res. 589(2): 81-102.

28.Zhang Y (2010) Ally isothiocyanate as a cancer chemopreventive phytochemical. Mol Nutr Food Res 54(1): 127-135.

29. Hwang ES, Bowen PE (2007) DNA damage, a biomarker of carcenogensis: its measurement and modulation by diet and environment. Cret Rev Food Science Nutr 47(1): 27-50.

30. Williamsons G, Plumb GW, Udas Y, Price KR, Rhoeds MJ (1996) Dietary quercetin glycoside: antioxidant activity and induction of the carcenogensis phase II marker enzyme quinone reductase Hepalclc7 cells. Carcenogensis (17)11: 2385-2387. 